\title{
Quality of life measures in Italian children with atopic dermatitis and their families
}

Fiorella Monti ${ }^{1}$, Francesca Agostini ${ }^{1 *}$, Francesca Gobbi ${ }^{2}$, Erica Neri ${ }^{1}$, Sandra Schianchi ${ }^{2}$ and Fabio Arcangeli ${ }^{2}$

\begin{abstract}
Background: The impact of atopic dermatitis (AD) on children's quality of life (QoL) in US and European countries is relatively well known, though rarely evaluated in the Italian population. Moreover, the association between child age and QoL has not been enough investigated, even though few studies detected a worse QoL in youngest AD children. The aim of the study was to evaluate the QoL in an Italian sample of atopic children and their families, also exploring a possible association with child age.

Methods: 60 AD children aged between 1-12 years and their mothers completed specific QoL questionnaires (IDQoL/CDLQI, DFI) and a clinician completed a measure of AD severity (SCORAD).

Results: AD severity (Objective SCORAD) significantly correlated with QoL measures. Severe AD children showed higher IDQoL/CDLQI and DFI scores compared to mild and moderate AD groups $(P=0.006$ and $P<0.0005$, respectively), but only DFI scores differed in these last two conditions $(P=0.014)$. DFI scores negatively correlated with children's age $(P=0.046)$, but did not differ when considering child age ranges. Multiple linear regression analyses revealed a significant association between Objective SCORAD and QoL measures.
\end{abstract}

Conclusions: A strong association between severe AD and poor QoL, both in children and mothers, was found in the Italian sample, in line with the international literature. Family's QoL scores were sensitively related to AD severity, more than the child's QoL, emphasising that the disease has a deep impact on the family. A significant association between age and QoL was only partially found and needs further investigation.

\section{Background}

Atopic dermatitis (AD), also known as atopic eczema, is one of the most common chronic inflammatory skin disease which occurs during childhood, affecting $10-20 \%$ of children in Europe [1], and 17\% of children in the United States [2]. Time trends in atopy have shown a substantial increase since the early 1960 s and there is evidence of consistent associations of these disorders with a Western lifestyle [3].

Usually childhood AD onsets in the first five years of life, with about $60 \%$ of cases appearing within the first year, frequently between 0 and 6 months [4].

Adverse consequences of this disorder on children, like distress, irritability, behavioural problems and sleep dysfunctions, have been reported in many previously published articles [5-8]. Besides, negative influences have

\footnotetext{
* Correspondence: f.agostini@unibo.it

'Department of Psychology, University of Bologna, Viale Berti Pichat 5, Bologna, Italy

Full list of author information is available at the end of the article
}

been observed in families, such as frustration, feelings of inadequacy about their role as parents, concerns, fears about the disease, self-blame and disappointments [4,7,9-14].

Recently, the detection of these adverse consequences have led to estimate the AD impact on the young patient's Quality of Life (QoL) [12,15-19], putting in evidence how a bad skin condition is frequently associated to a poorer QoL.

QoL is a wide concept, influenced by physical health, psychological state, level of independence and social relations. The World Health Organization (WHO) has tried to give quality of life (QOL) an exact definition: "The individual's perception of his position in life in the context of culture and value systems in which he lives and in relation to his goals, expectations, standards and concerns" [20].

In medicine, attempts to construct methods for measuring QOL have primarily focused on individuals with chronic diseases with elevated costs of care and treatment,

\section{() Biomed Central}


in order to better evaluate the impact of the disease on patients. A recent study [6] found that atopic children had a worse QoL than children affected by other chronic diseases (like, for example, naevi, acne, alopecia, diabetes, psoriasis, asthma, cystic fibrosis, generalised eczema), except cerebral palsy. Moreover, some studies evaluated the association between child's age and QoL, where a major impact was observed in children of youngest age $[21,22]$ and their families [21].

While several studies have explored prevalence of $A D$ and related QoL in childhood, in USA and European countries, to our knowledge few published studies have analysed these aspects in Italian children $[8,23,24]$.

The present study is a cross-sectional analysis, the aim of which was to investigate the impact of $\mathrm{AD}$ on the QoL of an Italian sample of atopic children and their families. The expected result is to find an association between a bad skin condition and a poorer QoL in children and their parents. Secondly, the study aimed at exploring a possible association between child's age and child's and family's QoL.

\section{Patients and Methods Study Subjects}

During the period March 2006-March 2007, all consecutive AD patients (aged 1-12 years), attending the Dermatology Unit of M. Bufalini Hospital, Cesena (Italy), and their mothers were considered eligible for the study and therefore asked to participate.

AD patients were enrolled in the study during a routine check-up in the Day-Hospital by a dermatologist, who registered the clinical profile and calculated the objective SCORAD, following the diagnostic criteria proposed by Hanifin and Rajka [25]. A psychologist then presented the research project to the mothers and their children; all subjects who were asked to participate consented to take part in the study and received the informed consent form and a range of questionnaires to complete: Infants Dermatitis Quality of Life Index (IDQoL), Children's Dermatology Life Quality Index (CDLQI), Dermatitis Family Impact (DFI). All questionnaires were completed entirely. For children aged 5-12 years, all the mothers completed the DFI, while their children completed the CDLQI; younger children's mothers helped them in understanding and filling in the questionnaires. For the children aged 1-4 years old, all mothers completed the DFI and the IDQoL.

Ethical approval ( ${ }^{\circ}$ PR 887026) for the study was obtained from the Hospital Ethics Committee.

\section{Instruments}

The instruments used in the study were:

The SCORAD [26], an index aimed at assessing AD disease severity, where the higher the value the worse the skin condition. Given that in literature [27] it has been demonstrated that subjective symptoms do not always correlate with disease severity and objective assessment, and in relation to the recommendations by Oranje et al. [27], we used the objective SCORAD, instead of the SCORAD index, including extent and intensity of the lesions, divided into three levels: < 15 mild, 15-40 moderate, $>40$ severe [27].

A questionnaire including items on the main sociodemographic characteristics.

The Infants Dermatitis Quality of Life Index (IDQoL [28]; Italian validated version [29]), a disease-specific measure for $\mathrm{AD}$ children between 0-4 years old, consisting of 10 items concerning physical and social functioning and completed by the caregiver. A total score is calculated (range 0-30), where higher scores represent a poorer quality of life.

The Children's Dermatology Life Quality Index (CDLQI), a skin-related measure for children between 5-16 years old [30], consisting of 10 items on physical and social functioning. The total score is between 0 and 30 , where higher scores represent a poorer quality of life.

The Dermatitis Family Impact questionnaire (DFI [13]; Italian validated version [29]), a 10-item scale measuring the impact of $\mathrm{AD}$ on families with a child affected by the disease, validated on a parents' sample of AD children aged 6 months- 10 years old; the total score is calculated and ranges from 0 to 30 , where, again, the higher the scores the poorer the quality of life.

\section{Statistical analysis}

Disease severity groups (mild, moderate, severe) were defined in function of the objective SCORAD ranges; patients were also classified in respect to specific age groups (1-4, 5-7 and 8-12 years), which were chosen considering main developmental stages [31,32].

Qualitative variables were compared using Chi Square test. Quantitative variables were analyzed first of all using correlations (Pearson's coefficient) and then using ANOVA; specifically, HRQoL scores of participants in different groups (according to AD severity levels and age groups) were compared using ANOVA and performing post hoc analyses with Tukeys Honestly Significant Difference (HSD) test. A multiple regression was performed in order to verify how much each variable contributed to an explanation of the HRQoL scores. All the following variables were included as predictors: child's gender, child's age, Objective SCORAD, presence of other allergies, caregiver's age, marital status and socio-economic level. Considering the low number of subjects, the Enter method was chosen as the safest one for the regression.

Statistical analyses were performed using the SPSS Package for Windows software, version 17.0. 


\section{Results}

\section{Clinical characteristics of the study subjects}

A total of $60 \mathrm{AD}$ children (range 1-12 years; mean \pm SD: $4.5 \pm 3.3$ ), including 30 females and 30 males, and their 60 mothers were recruited (range 25-50 years old; mean \pm SD: $36.5 \pm 5.8)$. Considering child age range, 37 children $(61.7 \%)$ were between 1 and 4 years old, 12 (20\%) between 5-7 years old and 11 (18.3\%) between 8-12. In $16.7 \%$ of cases, the children also suffered from another form of allergy, specifically cases of food allergy.

The majority of mothers were married (89.6\%); most of them had a permanent job (78.3\%): $48.3 \%$ of them were employees, $10 \%$ were self-employed and $20 \%$ worked in other fields. According to Hollingshead criteria for socioeconomic status [33], women were classified as belonging to one of three levels: low (27.1\%), medium (60.4\%) and high (12.5\%).

The mean Objective SCORAD score of the total sample was 29.46 ( \pm 16.31 ; range $3.5-74$ ); no significant differences emerged in the mean objective SCORAD score among the 3 children's age groups $(P=0.93)$ : children between 1-4 years old had a score equal to 28.81 ( \pm 14.85 ; range 3.5-59.5), 5-7 year old children scored 30.49 ( \pm 19.52; range 10-74), while 8-12 year old children scored 30.51 ( \pm 18.78; range 8.8-62), (Table 1 ).

According to the categories of the objective SCORAD, $26.7 \%$ (16) of children showed a mild AD, 50\% (30) a moderate AD and $23.3 \%$ (14) a severe AD. The distribution of children across AD severity levels and age ranges did not show any significant difference $\left(\chi^{2}=0.559, \mathrm{df}=2\right.$ $P=0.97$ ), (Table 1).

Also, the distribution of women in function of $\mathrm{AD}$ severity and levels of socio-demographic variables did not show significant differences (marital status: $P=0.25$; job: $P=0.34$; socioeconomic status: $P=0.64$ ).

\section{Correlations among SCORAD and QoL measures}

Correlations between Objective SCORAD and IDQoL/ CDLQI and DFI scores were all statistically significant, even though moderate $(r=0.401, P=0.001$ and $r=$ $0.414, P=0.001$, respectively). The correlation between DFI and IDQoL/CDLQI was high and significant $(r=$ $0.755, P<0.0001)$. Child's age negatively correlated with
DFI scores $(r=-0.258, P=0.046)$, but not with Objective SCORAD $(r=0.098, P=0.46)$ nor with IDQoL/CDLQI $(r=-0.119, P=0.367)$.

\section{Quality of life in relation to disease severity and child's} age: comparisons among patient groups

IDQoL/CDLQI mean score in the total sample was $7.0 \pm$ 5.21 (range 0-19). According to AD severity (Objective SCORAD categories), IDQoL/CDLQI mean scores appeared to be statistically different $(P=0.006)$ : post hoc analyses showed that the group with severe AD got a higher score compared to the group with mild $(P<$ $0.0005)$ and moderate $\operatorname{AD}(\mathrm{p}=0.038)$, but these last two were not statistically different $(P=0.063$; Table 2$)$. When considering child's age range, differences in IDQoL/ CDLQI mean scores did not emerge among groups $(P=$ 0.28 ; Table 2), not even when looking at the interaction between $\mathrm{AD}$ severity and age range $(P=0.87)$.

DFI mean score in the total sample was $7.95 \pm 6.21$ (range 0-23). DFI mean scores as well differed in relation to AD severity levels $(P<0.0005)$ : the group with severe AD showed a higher score compared to mild $(P<0.0005)$ and moderate AD groups $(P=0.024)$ and the latter was significantly higher than the mild group $(P=0.014$; Table 2). Further significant differences did not emerge when considering the child's age range variable $(P=0.074$; Table 2), nor when looking at "AD severity $\mathrm{x}$ child's age" $(P=0.99)$.

\section{Multiple linear regression of variables associated with QoL measures}

Using the Enter method, a significant model emerged $(P<0.037)$, in which $22 \%$ (Adjusted $\mathrm{R}^{2}=0.217$ ) of the variance in IDQoL/CDLQI scores was explained by Objective SCORAD (Beta coefficient $=0.479, P=$ 0.003 ), while all the other considered variables (sex, child's age, food allergies, mother's age, marital status, socio-economic level) did not significantly contribute to the variance (Table 3).

Considering DFI scores as criterion variable, a significant model emerged too $(P<0.008)$; again, Objective SCORAD (Beta coefficient $=0.558, P<0.0005)$ appeared to be the

Table 1 Objective SCORAD scores of 60 Children

\begin{tabular}{lcccc}
\hline \multicolumn{4}{c}{ AD Children } \\
\hline Objective SCORAD (mean \pm SD) & $\mathbf{1 - 4}$ years $(\boldsymbol{n}=\mathbf{3 7})$ & $\mathbf{5 - 7}$ years $(\boldsymbol{n}=\mathbf{1 2})$ & $\mathbf{8 - 1 2}$ years $(\boldsymbol{n}=\mathbf{1 1})$ & $\mathbf{p}$-value \\
Objective SCORAD severity & $28.81 \pm 14.85$ & $30.49 \pm 19.52$ & $30.51 \pm 18.78$ \\
Mild & - & - & - & 0.93 \\
Moderate & $10(27.0)$ & $3(25.0)$ & $3(27.3)$ & $5(45.5)$ \\
Severe & $18(48.6)$ & $7(58.3)$ & $3(27.3)$ \\
\hline
\end{tabular}

Figures in parentheses are percentages. 
Table 2 QoL measures in relation to AD severity and child's age

\begin{tabular}{|c|c|c|c|c|}
\hline \multicolumn{5}{|c|}{ Objective SCORAD } \\
\hline & $\begin{array}{c}\text { Mild } \\
(n=16)\end{array}$ & $\begin{array}{c}\text { Moderate } \\
(n=30)\end{array}$ & $\begin{array}{c}\text { Severe } \\
(n=14)\end{array}$ & $\mathrm{p}$-value \\
\hline IDQoL/CDLQI, mean \pm SD & $3.63 \pm 4.03$ & $7.0 \pm 4.70$ & $10.86 \pm 5.02$ & 0.006 \\
\hline $\mathrm{DFI}$, mean $\pm \mathrm{SD}$ & $3.38 \pm 5.02$ & $8.1 \pm 5.30$ & $12.79 \pm 5.30$ & $<0.0005$ \\
\hline \multicolumn{5}{|c|}{ Age groups } \\
\hline & $\begin{array}{c}1-4 \text { years } \\
(n=37)\end{array}$ & $\begin{array}{l}5-7 \text { years } \\
(n=12)\end{array}$ & $\begin{array}{l}\text { 8-12 years } \\
(n=11)\end{array}$ & p-value \\
\hline IDQoL/CDLQI, mean \pm SD & $7.57 \pm 5.02$ & $6.83 \pm 4.17$ & $5.27 \pm 6.77$ & 0.28 \\
\hline $\mathrm{DFI}$, mean $\pm \mathrm{SD}$ & $9.32 \pm 6.37$ & $6.08 \pm 5.52$ & $5.36 \pm 5.41$ & 0.074 \\
\hline
\end{tabular}

Data are means \pm SD

only significant predictor, explaining $31 \%$ of the variance (Adjusted $\mathrm{R}^{2}=0.308$ ) (Table 3 ).

\section{Discussion}

To our knowledge, the current study is one of the few published investigating QoL in an Italian sample of children with atopic dermatitis.

Globally, the results showed a strong association between QoL and disease severity, measured by Objective SCORAD, as already shown by international literature $[16,17,19]$. In fact, the study found that a bad skin condition was significantly associated with a poorer child QoL and with a significant worsening of family's QoL, evidencing how AD tends to affect the whole family system and not only the individual patient. Compared to a similar Italian study by Ricci et al. [8], including $45 \mathrm{AD}$ children aged between 3 months-7 years old, our children and families' QoL scores were noticeably lower, but we must consider that a higher percentage of severe AD was present in that sample $(44.4 \%$ severe AD children vs $23.3 \%$ in our study).
Looking into the details of our results and considering both individual patients' and families' QoL scores, we found some similarities and differences between the two.

First of all, both QoL scores showed a moderate correlation with Objective SCORAD, reporting very similar coefficients; the scores also showed to be significantly higher in severe AD children, compared to moderate and mild AD conditions. That is, poorer QoL was strictly associated to a more serious AD condition.

At the same time, differences between patients' and families' perspectives emerged in relation to the following aspects: while IDQOL/CDLQI scores were almost equal in moderate and mild AD children, DFI scores showed significant differences across all the 3 levels of AD severity. This means that, in our sample, families' QoL appeared to be noticeably affected by the intensity and severity of the child disease, more than the individual QoL. This aspect emphasises the main role played by the family in the management of the disease and should be more frequently kept in mind by clinicians.

Table 3 Contribution of sociodemographic and clinical variables to QoL measures

\begin{tabular}{llccc}
\hline & Predictor Variables & $\boldsymbol{\beta}$ values & $\boldsymbol{t}$ & $\mathbf{p}$-value \\
\hline IDQoL/CDLQI scores & Sex & -0.158 & -1.067 & 0.294 \\
& Age & -0.122 & -0.624 & 0.537 \\
Objective SCORAD & 0.479 & 3.190 & 0.003 \\
Food allergies & -0.197 & -1.242 & 0.223 \\
& Mother's age & 0.198 & 1.012 & 0.319 \\
& Marital status & -0.195 & -1.249 & 0.221 \\
Socio-economic level & 0.144 & 0.963 & 0.348 \\
SexI scores & Age & -0.197 & -1.375 & 0.179 \\
& Objective SCORAD & -0.174 & -0.943 & 0.363 \\
& Food allergies & 0.558 & 3.958 & 0.000 \\
& Mother's age & -0.205 & -1.375 & 0.179 \\
& Marital status & 0.013 & 0.071 & 0.944 \\
\end{tabular}


Another difference that emerged between IDQOL/ CDLQI and DFI measures was that only the latter appeared to be associated with child's age. In fact, DFI scores showed a negative correlation, even if weak, with the child's age: the parents of younger AD children seemed to experience a poorer QoL, as already suggested in the study by Ganemo et al. [21]. Anyway, given the small size of our sample, the non significant $P$ value detected when considering DFI scores in relation to different age groups $(P=0.074)$ and the non-relevance of the child's age as predictor variable in regression analysis, more investigations are needed.

The study has nevertheless some limitations. First of all, difficulties in recruiting the subjects have resulted in a limited sample size and a reduced number of considered variables and, because of this, further analyses on wider Italian samples are needed in future to obtain more statistically and clinically relevant data. Secondly, we had no control group and this did not allow the comparison between our results and the QoL of healthy children or children affected by other dermatological diseases. In future studies, therefore, it would be relevant to investigate whether in the Italian population the trends shown in literature, where AD subjects exhibit poorer QoL compared to control groups or other clinical groups, are confirmed $[6,19]$.

\section{Conclusions}

However, globally our data support the main clinical implications derived from recent international studies on QoL in atopic children; as underlined by Brenninkmeijer et al. [34], "in cases of severe AD, dermatologists should not only be attentive to the physical aspects but also to the psychological and social aspects of AD. In conclusion, we believe that in clinical care a systematic evaluation of physical and psychosocial consequences in patients with AD is warranted". Understanding HRQoL in the patient and his/her family might help professional operators to improve their relationship with them and to facilitate the management of treatment regimes. While early investigations tended to focus on socio-demographic and clinical variables, recent studies have shown that there are multiple factors which determine adherence, such as personal perception of health status, coping style, worries, burden, social reasons, motivation and side effects of treatments [6,35]. Warschburger et al. [36] have underlined how parental disease management is predicted by familial situation, personal well-being and severity of child disease.

For these reasons, it would be useful in future studies to focus on psychosocial and psychological variables that could affect families' QoL, such as analysing whether there is a substantial difference in mother and father's perceptions, as investigated by Holm et al. [37] and Chernishov [38], or if comorbidity with other parents' diseases can have some influence on their ability to provide the child with adequate care. At the same time, studies examining the effects of education programs on parental support should be promoted [39].

\section{Acknowledgements}

We would like to thank all the parents and the children for helping with this study and the valuable assistance of the staff at the Dermatology Unit, M. Bufalini Hospital, Cesena, Italy.

We give special thank to Francesca Lupi, psychologist, for data collecting and processing; we thank Valentina De Giglio, psychologist, for help with data collecting.

\section{Author details}

'Department of Psychology, University of Bologna, Viale Berti Pichat 5, Bologna, Italy. ${ }^{2}$ Dermatology Unit, M. Bufalini Hospital, Cesena, Italy.

\section{Authors' contributions}

FM and FG conceived the study and coordinated it. FA and EN performed the statistical analysis and drafted the manuscript. SS and FAR participated in the design of the study.

\section{Competing interests}

The authors declare that they have no competing interests.

Received: 18 July 2011 Accepted: 22 December 2011

Published: 22 December 2011

\section{References}

1. Hanifin JM: Epidemiology of atopic dermatitis. Immunol Allergy Clin North Am 2002, 22:1-24.

2. Laughter D, Istvan JA, Tofte SJ, Hanifin HM: The prevalence of atopic dermatitis in Oregon schoolchildren. J Am Acad Dermatol 2000, 43:649-655.

3. Von Hertzen LC, Haahtela T: Asthma and atopy-the price of affluence? Allergy 2004, 54:124-137.

4. Spergel JM, Paller AS: Atopic dermatitis and the atopic march:. J Allergy Clin Immunol 2003, 112:S118-S127.

5. Chamlin SL, Mattson CL, Frieden IJ, Williams ML, Mancini AJ, Cella D, Chren MM: The price of pruritus: sleep disturbance and co-sleeping in atopic dermatitis. Arch Pediatr Adolesc Med 2005, 159:745-750.

6. Beattie PE, Lewis-Jones MS: A comparative study of impairment of quality of life in children with skin disease and children with other chronic childhood diseases. Br J Dermatol 2006, 155(Suppl. 1):145-151.

7. Chamlin S: The psychosocial burden of childhood atopic dermatitis. Dermatol Ther 2006, 19:104-107.

8. Ricci G, Bendandi B, Bellini F, Patrizi A, Masi M: Atopic dermatitis: quality of life of young Italian children and their families and correlation with severity score. Pediatr Allergy Immunol 2007, 18:245-249.

9. Charman CR, Morris AD, Williams HC: Topical corticosteroids phobia in patients with atopic eczema. $\mathrm{Br} J$ Dermatol 2000, 142:931-936.

10. Finlay AY: Quality of Life in atopic dermatitis. J Am Acad Dermatol 2001, 45(Suppl. 1):64-66.

11. Chamlin SL, Frieden IJ, Williams ML, Chren MM: The effects of atopic dermatitis on young American children and their families. Pediatrics 2004 114:607-611.

12. Ben-Gashir MA, Seed PT, Hay RJ: Are quality of family life and disease severity related in childhood atopic dermatitis? J Eur Academy Dermatol Venereol 2002, 16(Suppl. 5):455-462.

13. Lawson V, Lewis-Jones MS, Finlay AY, Reid P, Owens RG: The family impact of childhood atopic dermatitis: The Dermatitis Family Impact questionnaire. Br J Dermatol 1998, 138:107-113.

14. Elliot BE, Luker $\mathrm{K}$ : The experiences of mothers caring for a child with severe atopic eczema. J Clin Nurs 1997, 6:241-247.

15. Fivenson D, Goldberg Arnold RJ, Kaniecki DJ, Cohen JL, Frech F, Finlay AY: The effect of Atopic Dermatitis on Total Burden of Illness and Quality of Life on Adults and Children in a Large Managed Care Organization. J Manag Care Pharm 2002, 8(Suppl. 5):333-342. 
16. Kiebert G, Soresen SV, Revicki D, Fagan SC, Doyle JJ, Cohen J, Fivenson D: Atopic dermatitis is associated with a decrement in Health-related quality of life. Int J Dermatol 2002, 41:151-158.

17. Ben-Gashir MA, Seed PT, Hay RJ: Quality of life and disease severity are correlated in children with atopic dermatitis. Br J Dermatol 2004, 150(Suppl. 2):284-290.

18. Zuberbier T, Orlow SJ, Paller AS, Taieb A, Allen R, Hernanz-Hermosa JM, Ocampo-Candiani J, Cox M, Langeraar J, Simon JC: Patient perspectives on the management of atopic dermatitis. J Allergy Clin Immunol 2006 118:226-232

19. Mozaffari H, Pourpak Z, Pourseyed S, Farhoodi A, Aghamohammadi A, Movahadi M, Gharaghozloo M, Moin M: Quality of life in atopic dermatitis patients. J Microbiol Immunol and Infect 2007, 40(Suppl. 3):260-264.

20. The WHOQOL Group: The World Health Organization quality of life assessment (WHOQOL): Position paper from The World Health Organization. Soc Sci Med 1995, 41:1403-1409.

21. Ganemo A, Svensson A, Lindberg M, Wahlgren CF: Quality of life in Swedish Children with Eczema. Acta Derm Veneorol 2007, 87:345-349.

22. Hon KLE, Leung TF, Wong KY, Chow CM, Chuh A, NG PC: Does age or gender influence quality of life in children with atopic dermatitis? $\mathrm{Br} J$ Dermatol 2008, 33:705-709.

23. Girolomoni G, Abeni D, Masini C, Sera F, Ayala F, Belloni-Fortina A, Bonifazi E, Fabbri P, Gelmetti C, Monfrecola G, Peserico A, Seidenari S, Giannetti A: The epidemiology of atopic dermatitis in Italian schoolchildren. Allergy 2003, 58:420-425.

24. Naldi L, Parazzini F, Gallus S, GISED study centres: Prevalence of Atopic Dermatitis in Italian Schoolchildren: Factors Affecting its Variation. Acta Derm Venereol 2009, 89:122-125.

25. Hanifin J, Rajka G: Diagnostic features of atopic dermatitis. Acta Derm Venereol (Stockh) 2000, 80:430-434.

26. European Task Force on Atopic Dermatitis: Severity scoring of atopic dermatitis, the SCORAD index: consensus report of the European Task Force on Atopic Dermatitis. Dermatology 1993, 186:23-31.

27. Oranje AP, Glazenburg EJ, Wolkerstorfer A, Tasset C, de Longueville M: Practical issues on interpretation of scoring atopic dermatitis: the SCORAD index, objective SCORAD and the three-item severity score. $\mathrm{Br} J$ Dermatol 2007, 157(Suppl. 4):645-648.

28. Lewis-Jones MS, Finlay AY, Dykes PJ: The Infants' Dermatitis Quality of Life Index. Br J Dermatol 2001, 144:104-110.

29. Baranzoni N, Scalone L, Mantovani LG, De Portu S, Monzini M, Giannetti A: Validazione della versione Italiana dell'Infants' Dermatitis Quality of life and Family Dermatitis Indexes. G Ital Dermatol Venerol 2007, 142(Suppl. 5):423-432.

30. Lewis-Jones MS, Finlay AY: The Children's Dermatology life Quality Index (CDLQI), initial validation and practical use. Br J Dermatol 1995, 132:942-949.

31. Brazelton TB, Greenspan SI: The Irreducible Needs of Children: What Every Child Must Have to Grow, Learn, and Fluorish Cambridge: Perseus Books; 2000.

32. Shapiro T, Perry P: Latency revised. Psychoanalitic Study Child 1976, 31:79-105.

33. Hollingshead AA: Four-factor index of social status Yale University, New Haven, CT; 1975, Unpublished manuscript Available at http://www.yale.edu/ sociology/faculty/docs/hollingshead_socStat4factor.pdf.

34. Brenninkmeijer EE, Legierse CM, Smitt JH, Last BF, Grootenhuis MA, Bos JD: The Course of Life of Patients with Childhood Atopic Dermatitis. Pediatr Dermatol 2009, 26(Suppl. 1):14-22.

35. Staab D, von Rueden U, Kehrt R, Michael Erhart M, Kerstin Wenninger K, Panagiotis Kamtsiuris $\mathrm{P}$, Wahn U: Evaluation of parental training program for the management of childhood atopic dermatitis. Pediatr Allergy Immunol 2002, 13(Suppl. 2):84-90

36. Warschburger P, Buchholtz $H$, Petermann F: Psychological adjustment in parents of young children with atopic dermatitis: which factors predict parental quality of life? Br J Dermatol 2004, 150:304-311.

37. Holm EA, Esmann $S$, Jermec GBE: Parent gender and assessment of infant life quality. J Eur Academy Dermatol Venereol 2006, 20:274-276.

38. Chernyshov PV: May the gender of a parent influence assessment of health related quality of life, family impact and severity of atopic dermatitis in children? Pediatr Dermatol 2009, 26(Suppl. 1):99-100.

39. Kupfer J, Gieler U, Diepgen TL, Lob-Corziliuse T, Ringf J, Scheeweg S, Scheidtc R, Schnoppf C, Szczepanskie R, Staab D, Werfeli T, Wittenmeierj M,
Wahnh U, Schmid-Ott G: Structured education program improves the coping with atopic dermatitis and their parents-a multicenter, randomized controlled trial. J Psicosom Res 2010, 68:353-358.

doi:10.1186/1824-7288-37-59

Cite this article as: Monti et al:: Quality of life measures in Italian children with atopic dermatitis and their families. Italian Journal of Pediatrics 2011 37:59.

\section{Submit your next manuscript to BioMed Central and take full advantage of:}

- Convenient online submission

- Thorough peer review

- No space constraints or color figure charges

- Immediate publication on acceptance

- Inclusion in PubMed, CAS, Scopus and Google Scholar

- Research which is freely available for redistribution

Submit your manuscript at www.biomedcentral.com/submit
Biomed Central 